\title{
HUMAN IMMUNODEFICIENCY VIRUS-HEPATITIS C VIRUS COINFECTION: A REVIEW ON NECESSITY OF DIETARY COMPOUNDS FOR ANTIRETROVIRAL THERAPY
}

\author{
SUGANYA SELVARAJ, SHANMUGHAVEL PIRAMANAYAGAM* \\ Computational Biology Lab, Department of Bioinformatics, Bharathiar University, Coimbatore - 641 046, Tamil Nadu, India. \\ Email: shanmughavel@buc.edu.in
}

Received: 23 March 2018, Revised and Accepted: 30 April 2018

\begin{abstract}
Human immunodeficiency virus (HIV)-hepatitis C virus (HCV) coinfection is a major health problem around worldwide. One-third of the HIV-infected patients suffer from chronic hepatitis (HCV). The risk factors of coinfected patients are very high while compared to the monoinfected patients; they are having higher HCV viral load is associated with a severe liver damage. The use of highly active antiretroviral therapy (HAART) dramatically increases the survival of HIV/HCV-coinfected patients by preventing the depletion of CD4 cell counts and delaying the progression of fibrosis which reduces the complications related to end-stage liver damage. Reverse-transcriptase inhibitors and protease inhibitors are very commonly used drugs for the treatment of coinfection. Combination drugs and synthetic drugs are playing a pivotal role in the coinfection therapy. Under HAART, the coinfected patients are affected by many adverse effects such as mitochondrial toxicity, hypersensitivity, and lipodystrophy syndrome. However, the adverse effects of most herbal drugs are relatively less frequent when the drugs are used properly compared with synthetic drugs; it may help to protect the patients from severe adverse effects. This review collates to the importance of plant-derived drugs for the treatment of HIV-HCV coinfection.
\end{abstract}

Keywords: Human immunodeficiency virus-hepatitis C virus coinfection, Dietary compounds, Antiretroviral therapy, Transcriptase inhibitors, Side effects, Genotype.

(C) 2018 The Authors. Published by Innovare Academic Sciences Pvt Ltd. This is an open access article under the CC BY license (http://creativecommons. org/licenses/by/4. 0/) DOI: http://dx.doi.org/10.22159/ajpcr.2018.v11i8.26176

\section{INTRODUCTION}

Acquired immune deficiency syndrome (AIDS) is caused by the human immunodeficiency virus (HIV). It affects the immune system by the depletion of CD4 cell counts; human body dramatically loses its immune power fights against infection [1]. With CD4 counts $<200$ cells/ $\mu \mathrm{l}$, patients are at high risk for developing opportunistic infections such as hepatitis, tuberculosis, and etcetera [2]. Most of the HIV-infected patients were affected chronic hepatitis C virus (HCV), a coinfection which is rapidly emerging as a major cause of morbidity and mortality throughout the world. HCV is a leading cause of chronic liver disease [3], long-term complications of HCV infection include cirrhosis, end-stage liver disease, and hepatocellular carcinoma [4]. The most common mode of transmission was sexual promiscuity (79\%), followed by spouse positivity $(15 \%)$ and history of blood transfusion $(6 \%)$ [5]. The widespread of highly active antiretroviral therapy (HAART), since 1996 has radically changed the natural history of HIV infections, given in the reduction of HIV/HCV pathogenicity. The gradual progress of CD4 counts and undetectable HIV plasma viral load is associated with a slower rate of liver fibrosis progression in HIV/HCVcoinfected patients [5], in spite of disturbed glutathione redox status and decreased antioxidant levels seem to persist even during HAART [6]. Before the availability of antiretroviral therapy (ARVT), median survival after diagnosis of AIDS was 12-18 months [2]. Unfortunately, up to $25 \%$ of patients discontinue their initial HAART regimen because of treatment failure (inability to suppress HIV viral replication to below the current limit of detection, 50 copies $/ \mathrm{ml}$ ) [7]. $12-25 \%$ of patients discontinued therapy early (12 weeks) because of either cost or severe adverse effects [8]. In contrast to modern medicines, herbal medicines are frequently used to treat chronic diseases. Combinations with chemically defined as active substances or isolated constituents are not considered to be herbal medicines. However, the adverse effects of phytotherapeutic agents are less frequent compared with synthetic drugs, several regulatory models for herbal medicines are currently available, including prescription drugs, over-the-counter substances, traditional medicines, and dietary supplements [9].

\section{EPIDEMIOLOGY}

HCV is the cause of more than three-quarters of liver-related deaths in HIV-seropositive participants, and it is incredible that at present roughly one-quarter of HIV-infected contributors in Europe and the US have $\mathrm{HCV}$ coinfection. HIV/HCV-coinfected patients, who are more likely to develop cirrhosis, had an improved risk of developing AIDS, of HIVassociated ailment and of overall mortality [10]. How HCV may have an impact on the direction of HIV contamination will not be well known even though it used to be prompt that HCV co-contamination is capable to develop immune activation and to sensitize CD4+T-cells closer to apoptosis in the absence of an HIV remedy [10]. The most predominant HCV genotypes among coinfected individuals were type 1 (80\%), $3(12 \%)$, and $4(6 \%)$. There is no case bearing genotype 2 [11]. There is a lot of evidence that suggests the simultaneous presence of HIV contamination accelerates the liver damage from HCV favoring the evolution to cirrhosis in cocontaminated sufferers. HIV growing of TNF-alpha liver construction and of HCV replication in peripheral blood lymphomonocytes is the mechanisms on the groundwork of this phenomenon. HAART had a constructive result of HIV/HCV coillness; in any other case, it does no longer appear to entirely proper the adversarial result of HIV illness on HCV-related outcomes [10].

\section{Global scenario}

Globally, a predicted ratio of HIV patients are 40 million and HCV patients are 130 million. In HIV-contaminated persons, an estimated 4-5 million have HCV co-contamination. HCV and HIV share original routes of transmission, but they differ in their occurrence with the aid of geographic vicinity and the effectivity by which targeted types of exposures transmit them. Among HIV optimistic people studied from Western Europe and the US, power HCV infection has been found in $25-30 \%$ of HIV-positive persons total $72-95 \%$ of injection drug customers, $1-12 \%$ of men who have sex with men, and $9-27 \%$ of heterosexuals [12].

HIV-HCV occurrence varies extensively among risk groups, with a prevalence of $59 \%$ in cohorts of injection drug use (IDU) in the 
US and Europe [13] and as much as 85\% in hemophiliacs with HIV [14]. A hepatic disease has become the leading non-AIDS intent of morbidity and mortality among HIV-contaminated participants after the availability of antiretroviral (ART) medication grew to be fashionable in useful resource adequate areas of the world. In a 2006, multinational cohort of more than 25,000 HIV-infected individuals in the USA and Europe, $14 \%$ of the deaths have been liver associated and, of those, $66 \%$ passed off in people with concomitant HCV infection [15]. In the United States, approximately $80 \%$ of the HIVHCV-coinfected patients were influenced by HCV genotype 1 [16], and end-stage liver disease is an important cause of death $[17,18]$. Similar HCV prevalence rates have been demonstrated among HIV-contaminated populations in France, Germany, Switzerland, and Greece [10]. Observation among urban IDU found coinfection prevalence rates of $84 \%$ and $88 \%$ [19-21].

\section{Indian scenario}

The first HIV estimation in India was done by the National AIDS Control Organization and Ministry of Health and Family welfare [22]. In India, coinfection with hepatitis $\mathrm{C}$ has been found to be associated with almost an 8-fold increased risk of disease progression [23], the rates of coinfection with HIV and HCV are reported to be 6-33\% [23,24]. The mean survival time of Indian patients after diagnosis of HIV is 92 months [2]. The Eastern state of Manipur 92\% of HIV-positive intravenous drug users (IVDUs), were coinfected with hepatitis C [25]. Slum areas in Chennai IVDUs are 28 times more likely to be HCV infected than those denying IDU [26]. In a predominantly non-IVDU population, HIV-HCV coinfection rates have been reported between 4.8 and $21.4 \%$ [27]. The first HIV estimation in India was done by the National AIDS Control Organization and Ministry of Health and Family welfare [22]. The prevalence in high-risk groups came to over $5 \%$ by 1990 [28]. According to UNDPs 2010 report, India had 2.395 million individuals living with HIV toward the end of 2009, up from 2.27 million in 2008. Grown-up commonness additionally ascended from $0.29 \%$ in 2008 to $0.31 \%$ in 2009 [29]. Two studies from Lucknow and Chennai showed relatively low rates of coinfection of $1.61 \%$ and $2.2 \%$, respectively $[30,31]$. Both these studies were done in patients with a low incidence of IVDU. However, a report from Imphal studied coinfection of HIV and HCV in injecting IVDUs and found a very high rate of $52.4 \%$ [32].

\section{RISK FACTORS OF HIV/HCV COINFECTION}

Once, a person affected by HIV, the virus enters the white blood cells called CD4 lymphocytes and starts to replicate itself. Human body tries to defend itself against HIV by producing antibodies. These cells help to get rid of some virus. After an acute HIV injection, body continuously produces an enormous rate of antibodies to fight infection. Even though human body still has an HIV infection, the usual blood tests will be normal. However, during this time the virus is still attacking the lymph nodes (centers of the body's immune system). Over 10-15 years, HIV would kill so many CD4 cells that a human body could no longer fight off infections. At this point, the person is diagnosed as having AIDS [33]. The reduction of $\mathrm{CD} 4$ cell counts is at high risk for developing opportunistic infections like hepatitis [2]. Most of the HIV/HCV-coinfected patients have abnormal levels of transaminases; it leads to liver fibrosis on biopsy. A normal rate of alanine aminotransferase does not allow the progression of liver fibrosis [5]. Compared to monoinfected patients, the treatment procedure of coinfected peoples is a complicated one. Majority of coinfected individuals drops their treatment because of severe anemia and an adverse effect of retroviral therapy [2,34]. Cryptococcal meningitis is a common threat to HIV patients which caused by Cryptococcus neoformans; it is most commonly affect the immunocompromised (people have an impaired or weakened immune system) patients [35]. In some occasion, HIV infection becomes severe when the rapid rises in plasma viremia with a concomitant drop of the CD4 count within 3-6 weeks [5]. Pregnant women and diabetic patients, who under the treatment of dialysis affected more due to the severity of coinfection [36].

\section{THERAPEUTIC IMPLICATIONS}

HAART (a combination of at least three drugs) plays an important role in the treatment of HIV/HCV-coinfected patients [37]. Three classes of drugs are used to treat HIV such as protease inhibitor (PI), nucleoside reverse transcriptase inhibitors, and non-nucleoside reverse transcriptase inhibitors [33]. In 1996, PI therapy became widely available only after the cytarabine trial [38,39]. Combination regimens of pegylated interferons (PEG-IFN) and ribavirin induce a sustained response in $42-82 \%$ of patients with chronic hepatitis C, depending on genotype $[40,41]$. It is an optimal therapy for chronic hepatitis C among HIV-infected patients [42]. The use of anti-HCV PI drugs, boceprevir, and telaprevir in coinfected persons seems to illustrate a greater antiviral efficacy within the HIV/HCV coinfected population [43]. Different combination regimens reduce the risk of liver-related complications, sustained virological rates between $27 \%$ and $44 \%[5,44]$. There is no cure for the HIV which causes AIDS, but a combination of drugs can keep the virus away from replicating and damaging the immune system [33]. Combination regimens given to the patients depend on the types of hepatitis $\mathrm{C}$ genotypes. Some regimens were listed in Table 1 [45].

\section{SIDE EFFECTS OF ARVT}

ART toxicity is a major issue in the management of coinfected patients. In general, HAART has been shown to be safe and well effective at increasing the lifespan of HIV/HCV-coinfected patients. Similarly, patients under the medication of HAART face severe adverse effects and toxicities including vomiting, fatigue, irritability, depression, anemia, hepatitis, pancreatitis, peripheral neuropathy, lipoatrophy, lipodystrophy, Stevens-Johnson syndrome (SJS), leukopenia, diarrhea, and weight loss $[5,46,47]$. The risk of side effects varies from drug to drug and from patients to patients [25]. Lipodystrophy was noted primarily in patients with stavudine-based HAART, whereas hypersensitivity syndrome, hepatitis, and SJS were associated with the use of nevirapine [2]. Leukopenia and thrombocytopenia are shown a dose-related adverse effect of PEG-IFN, granulocyte colonystimulating factor used in the drug formation it improves diarrhea [48]. Didanosine (DDI) has been associated with severe mitochondrial toxicity, leading to pancreatitis, hepatic failure, and death [5]. Unconjugated hyperbilirubinemia can occur with a PI, indinavir. Drugs, Invirase and Norvir, lead to an abnormal heart rhythm. Notably approved PIs have gastrointestinal side effects [33]. More recently, two animal studies reveal tenofovir disoproxil fumarate (TDF)-based

Table 1: Various potential DDA oral combination regimens used for treatment based on the types of hepatitis $\mathrm{C}$ genotypes

\begin{tabular}{ll}
\hline $\begin{array}{l}\text { Different types of } \\
\text { hepatitis C genotypes }\end{array}$ & $\begin{array}{l}\text { Potential DDA oral combination } \\
\text { regimens }\end{array}$ \\
\hline Genotype 1 & Elbasvir/grazoprevir \\
& Ledipasvir/sofosbuvir \\
& Paritaprevir/ritonavir/ \\
& ombitasvir+dasabuvir \\
& Simeprevir+sofosbuvir \\
& Sofosbuvir/velpatasvir \\
& Daclatasvir+sofosbuvir \\
& Daclatasvir with sofosbuvir \\
& Sofosbuvir/velpatasvir \\
Eenotype 2 & Elbasvir/grazoprevir+sofosbuvir \\
& Daclatasvir with sofosbuvir \\
Genotype 3 & Sofosbuvir/velpatasvir \\
& Paritaprevir/ritonavir/ombitasvir \\
Genotype 4 & Sofosbuvir/velpatasvir \\
& Elbasvir/grazoprevir \\
& Ledipasvir/sofosbuvir \\
& Sofosbuvir/velpatasvir \\
Lenotype 5 or 6 & Ledipasvir/sofobuvir \\
& Elbasvir/grazoprevir \\
&
\end{tabular}

DDA: Direct drug activity 
Table 2: Different combination regimens of NRTIs and their toxic effects

\begin{tabular}{ll}
\hline NRTIs & Common side effects \\
\hline Ziagen (abacavir) & Hypersensitivity reaction \\
Combivir (lamivudine+zidovudine) & Anemia \\
Videx, or Videx-EC (didanosine or ddl) & Diarrhea, abdominal pain, neuropathy, nausea, vomiting, pancreatitis \\
Emtriva (emtricitabine) & Rash and skin darkening of palms or soles, numbness, tingling, or burning sensation \\
Epzicom (abacavir+lamivudine) & Nausea, vomiting, upset stomach, diarrhea, fatigue, chills, dizziness, insomnia \\
Epivir (lamivudine) & Nausea, vomiting, upset stomach, diarrhea, fatigue, dizziness, headaches, insomnia \\
Zerit, Zerit XR (stavudine, d4T) & Peripheral neuropathy, headache, chills and fever, diarrhea, nausea, fat loss in arms, \\
& legs, or face \\
Viread (tenofovir) & Mild nausea, vomiting, loss of appetite, upset stomach \\
Trizivir (abacavir+zidovudine+lamivudine) & Anemia, nausea, stomach pain, diarrhea, constipation, vomiting, dizziness, \\
& insomnia, fatigue, muscle aches, hypersensitivity reaction \\
Truvada (tenofovir+emtricitabine) & Mild nausea, vomiting, loss of appetite, rash, darkening of palms or soles, tingling, \\
numbness or burning sensation \\
Retribild (tenofovir (AZT, zidovudine) & Nausea, diarrhea \\
Triumeq (abacavir+lamivudine+dolutegravir) & Anemia, nausea, vomiting \\
\hline
\end{tabular}

NRTIs: Nucleoside reverse-transcriptase inhibitors

Table 3: Different combination regimens of NNRTIs and their toxic effects

\begin{tabular}{ll}
\hline NNRTIs & Common side effects \\
\hline Edurant (rilpivirine) & $\begin{array}{l}\text { Depression, difficulty sleeping, headache, } \\
\text { rash }\end{array}$ \\
Vivid dreams, anxiety, rash, nausea, \\
insomnia \\
Viramune (nevirapine) & $\begin{array}{l}\text { Skin rash, fever, headache, nausea, } \\
\text { diarrhea }\end{array}$ \\
\hline
\end{tabular}

NNRTIs: Non-nucleoside reverse-transcriptase inhibitors

Table 4: Commonly used PIs for HIV/HCV coinfection and their adverse effects

\begin{tabular}{ll}
\hline PIs & Toxic effects \\
\hline Saquinavir (SQV) & Nausea, diarrhea \\
Ritonavir (RTV) & $\begin{array}{l}\text { Peripheral paresthesia, nausea, diarrhea, } \\
\text { flushing } \\
\text { Renal calculi, hyperbilirubinemia, reflux } \\
\text { esophagitis, retinoid effects, hemolytic } \\
\text { andinavir (IDV) }\end{array}$ \\
& Diarrhea, nausea, GI upset \\
Nelfinavir (NFV) & Hypersensitivity, perioral paresthesia \\
Amprenavir (APV) & Elevation of liver enzyme levels \\
Invirase (INV) & GI toxic effects, elevation of liver enzyme \\
Fortovase (FTV) & levels \\
\hline
\end{tabular}

PIs: Protease inhibitors, HIV: Human immunodeficiency virus, HCV: Hepatitis C virus, GI: Gastrointestinal

ART causes mtDNA depletion and mitochondrial dysfunction. TDFrelated (tenofovir+lamivudine+nevirapine regimen) renal impairment considered as an incessant inconvenience during treatment with TDF. Risk factors for developing renal impairment incorporate increasing age and CD4>200 cells [49]. Even though non-nucleotide reversetranscriptase inhibitors such as nevirapine, stavudine, DDI, and tipranavir indistinct had been related to the progress of hepatotoxicity, all ARVs are associated with some risk of hepatotoxicity. Some other regimens lead to the elevation of transaminases, which result in more than five times upper to cause the liver harm including viral hepatitis and other liver related diseases [50].

HCV-associated immune reconstitution inflammatory syndrome can arise after ART initiation, but it is a diagnosis of exclusion [47]. Hypersensitivity is an erythematous and confluent rash with or without fever; it is most prominent in the body and arms and usually begins after 1-3 weeks therapy. SJS or toxic epidermal necrolysis develops in less than $0 \bullet 5 \%$ of patients but has not been reported with abacavir [37]. Lipodystrophy syndrome is a cause of peripheral fat loss (presumed lipoatrophy in the face, limbs, and buttocks) and central fat accumulation (within the abdomen, breasts, and over the dorsocervical spine (so-called "buffalo hump)," as well as other lipomata [7,51]. Neither cytarabine nor regimens of one or two reversetranscriptase inhibitors affect the course of progressive multifocal leukoencephalopathy in patients infected with the HIV [52]. A list of some reverse-transcriptase inhibitors (RTIs) and their medication side effects are presented in Table 2 [53] and 3 [54].

Like transcriptase inhibitors, many PIs (HIV1 PI) are available in the market for the treatment of coinfection such as saquinavir, ritonavir, and etcetera. These PIs also possess different kinds of side effects depend on the dose prescribed, age, and severity of illness. Some kind of PI and its side effects listed in Table $4[37,54]$.

\section{MEDICINAL PLANTS IN AVRT}

Many medicinal plants have antiviral properties, from these few plants which have high anti-HIV activity. The trend in the domestication, production and biotechnological studies and genetic improvement of medicinal plants, instead of the use of plants harvested in the wild, will offer great advantages since it will be possible to obtain uniform and high-quality raw materials which are fundamental to the efficacy and safety of herbal drugs [9]. Epigallocatechin-3-gallate (EGCG), one of the components of green tea, has been suggested to have antiviral activity; EGCG strongly inhibited the replication of HIV. Glutamine is an antioxidant nutritional supplement extracted from herbs can increase body weight, cell mass, and intracellular water when compared with placebo in HIV patients. Hyssop has antiviral activity against herpes simplex and HIV. Licorice, Rooibos tea, Echinacea herb, and Catuaba (an Amazonian plant) may have some anti-HIV activity. Olive leaf extract prevents the cell-cell transmission of HIV. Korean red ginseng helps to increase the count of CD4 cells. Bovine colostrums may reduce the severity of diarrhea in HIV patients. Fish oils reduce the HIV infection to reduce triglycerides and also prevent cardiovascular disease [33].

Thailand and China introduced an herbal drug called SH instant, which strengthen the immune systems of people with HIV and help to control the viral replication. It is a combination of five different medicines, from these three medicinal herbs from are China and two from Thailand. Chinese herbs are Yinchen, Huanggi, and Gancho with pluak rak mon (part of the mulberry root) and Dok kham foi (extracted from safflowers) [33]. Silybim marianum (milk thistle), Glycyrrhiza glabra, Picrorhiza kurroa, and Phyllanthus amarus are confirmed as safe and hepatoprotective herbals used for repairing liver function, 
Table 5: List of active dietary molecules has anti-HIV-HCV properties and their plant

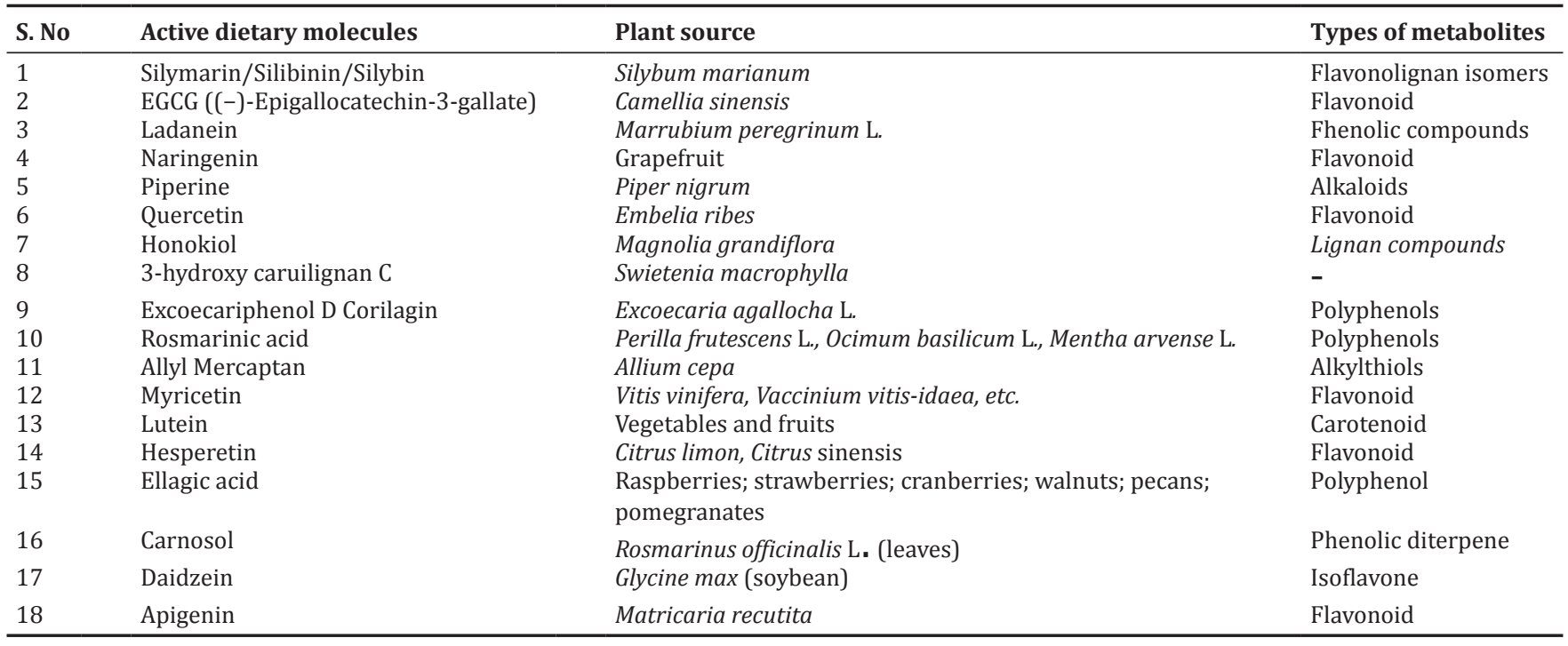

including cirrhosis. A clinical trial with Phyllanthus niruri significantly reduces the chronic toxicity by maintaining the level of transaminases [55]. Orange juice is considered as a rich dietary source of antioxidants for patients with hepatitis C under antiviral therapy [56]. Medicinal herbs have a wide range of therapeutic use and are suitable for chronic treatments; the occurrence of undesirable side effects seems to be less frequent with herbal medicines, but well-controlled, randomized clinical trials have revealed that they also exist; they usually cost less than synthetic drugs [9]. Following table contains some examples of active dietary molecules, which possess the anti-HIV and HCV properties (Table 5) [57,58].

\section{CONCLUSION}

Synthetic drugs and combination regimens are most commonly used to treat coinfected patients. However, prolonged treatment with combination regimens can be difficult to sustain because of problems with adherence and toxic effects [59]. Instead of synthetic compounds, natural compounds reduce the risk of side effects and also possess antiviral activity. Natural substances work against HIV through other mechanisms as well. The bioactive components of dietary phytochemicals most often show to be effective against HIV/HCV, by their potential in preventing $\mathrm{HIV} / \mathrm{HCV}$ through modifying genetic and epigenetic targets.Comparing with synthetic medicine the course of herbal regimen is extended [9]. Hence, the future aims to find out many lead compounds from dietary phytochemicals that can exhibit the pathogenic role of both HIV and HCV. It will protect the people from the severe adverse effects of HIV-HCV coinfection medication. This study will promote the scientific study of dietary supplements for maintaining health and preventing chronic diseases.

\section{AUTHOR'S CONTRIBUTION}

Conceptualization, Data collection, Manuscript writing: Suganya Selvaraj. Final approval of Manuscript: Shanmughavel Piramanayagam

\section{CONFLICTS OF INTEREST}

The authors declare that they have no conflicts of interest.

\section{REFERENCES}

1. Levy JA. HIV and the Pathogenesis of AIDS. Washington, USA: American Society for Microbiology; 1994.

2. Kumarasamy N, Snigdha V, Timothy PF, Kenneth HM, Suniti S. Clinical profile of HIV in India. Indian J Med Res 2005;121:377-95.

3. Chen SL, Morgan TR. The Natural History of Hepatitis C Virus (HCV) Infection. Int J Med Sci 2006;3:47-52.
4. Chen YJ, Feeney RE, Chung TR. HCV and HIV co-infection: Mechanisms and management. Nat Rev Gastroenterol Hepatol 2014;11:362-71.

5. Chandra N, Joshi N, Raju YS, Kumar A, Teja DV. Hepatitis B and/or C co-infection in HIV infected patients: A study in a tertiary care centre from south India. Indian J Med Res 2013;138:950-4.

6. Kolgiri V, Patil VW, Nagar V. Correlation of total antioxidant status (TAS) with DNA damage in HIV/AIDS patients. Int J Pharm Pharm Sci 2016;8:240-4.

7. Montessori V, Press N, Harris M, Akagi L, Montaner JS. Adverse effects of antiretroviral therapy for HIV infection. Can Med Assoc J 2004;170:229-38.

8. Carr A, Samaras K, Burton S, Law M, Freund J, Chisholm DJ, et al. A syndrome of peripheral lipodystrophy, hyperlipidaemia and insulin resistance in patients receiving HIV protease inhibitors. AIDS 1998;12:F51-8.

9. Calixto JB. Efficacy, safety, quality control, marketing and regulatory guidelines for herbal medicines (phytotherapeutic agents). Braz J Med Biol Res 2000;33:179-89

10. Andreoni M, Giacometti A, Maida I, Meraviglia P, Ripamonti D, Sarmati L. HIV-HCV co-infection: epidemiology, pathogenesis and therapeutic implications. Eur Rev Med Pharmacol Sci 2012;16:1473-83.

11. Bessone F. HIV/HCV COINFECTION. Gaz méd Bahia 2009;79:24-7.

12. HIV/AIDS in India. Available from: https://www.en.wikipedia.org/ wiki/HIV/AIDS in India.

13. Thomas LD, Shih $\overline{\mathrm{W}} \mathrm{J}$, Alter JH, Vlahov D, Cohn S, Hoover RD, et al. Effect of human immunodeficiency virus on hepatitis $\mathrm{C}$ virus infection among injecting drug users. J Infect Dis 1996;174:690-5.

14. Zylberberg H, Pol S. Reciprocal interactions between human immunodeficiency virus and hepatitis $\mathrm{C}$ virus infections. Clin Infect Dis 1996;23:1117-25.

15. Weber R, Sabin CA, Friis-Møller N. Liver-related deaths in persons infected with the human immunodeficiency virus: The D: A: D study. Arch Intern Med 2006;166:1632-41.

16. Sherman KE, Rouster SD, Chung RT, Rajicic N. Hepatitis C virus prevalence among patients infected with human immunodeficiency virus: A cross-sectional analysis of the US Adult AIDS Clinical Trials Group. Clin Infect Dis 2002; 34:831-7.

17. Rockstroh JK, Spenglerb U. HIV and Hepatitis C Virus Infection. Lancet 2004;4:437-44.

18. Cox J, Hamelin AM. Linden MT, Moodie EE, Anema A, RolletKurhajec KC, et al. Food insecurity in HIV-Hepatitis C virus coinfected individuals in Canada: The importance of Co-morbidities. AIDS Behav 2017;21:792-802.

19. Weinstock DM, Merrick S, Malak SA, Jacobs J, Sepkowitz KA. Hepatitis $\mathrm{C}$ in an urban population infected with the human immunodeficiency virus. AIDS 1999;13:2593-5

20. Weissenbacher M, Rossi D, Radulich G, Sosa-Estáni S, Vila M, Vivas E, et al. High seroprevalence of bloodborne viruses among streetrecruited injection drug users from Buenos Aires, Argentina. Clin Infect 
Dis 2003;37:S348-52.

21. Shepard WC, Finelli L, Alter JM. Global epidemiology of hepatitis C virus infection. Lancet Infect Dis 2005;5:558-67.

22. ICMR Ministry of Health and Family Welfare Government of India. India HIV Estimations 2015 Technical Report. New Delhi: National AIDS Control Organisation and National Institute of Medical Statistics, ICMR Ministry of Health and Family Welfare Government of India.

23. Kumarasamy N, Solomon S, Flanigan TP, Hemalatha R, Thyagarajan SP, Mayer KH. Natural History of human immunodeficiency virus disease in south India. Clin Inf Dis 2003;36:79-85.

24. Sud A, Sigh J, Dhiman RK, Wanchu A, Singh S, Chawla Y. Hepatitis b virus coinfection in HIV infected patients. Trop Gastroenterol 2001;22:90-2

25. Saha MK, Chakrabarti S, Panda S, Naik TN, Manna B, Chatterjee A, et al. Prevalence of HCV and HBV infection amongst HIV seropositive intravenous drug users and their non-injecting wives in Manipur, India. Indian J Med Res 2000;111:37-9.

26. Marx MA, Murugavel KG, Sivaram S, Balakrishnan P, Steinhoff M, Anand $\mathrm{S}$, et al. The association of health care use and hepatitis $\mathrm{C}$ virus information in a random sample of urban slum community residents in southern India. Am J Trop Med Hyg 2003;68:258-62.

27. Battacharya S, Badrinath S, Hamide A, Sujatha S. Coinfection with hepatitis $\mathrm{C}$ virus and human immunodeficiency virus among patients with sexually transmitted diseases in Pondicherry, South India. Indian J Pathol Microbiol 2003;46:495-7.

28. World Health Organization. WHO Library Cataloguing-in-Publication Data Global health risks: Mortality and Burden of Disease Attributable to Selected Major Risks. Geneva: World Health Organization; 2009. Available from: http://www.who.int/healthinfo/global_burden_disease/ GlobalHealthRisks_report_full.pdf.

29. HIV/AIDS in India. Available from: http://www.en.wikipedia.org/wiki/ HIV/AIDS in India.

30. Saravanan $\overline{\mathrm{S}}$, Velu V, Kumarasamy N, Nandakumar S, Murugavel KG, Balakrishnan $\mathrm{P}$, et al. Coinfection of hepatitis $\mathrm{B}$ and hepatitis $\mathrm{C}$ virus in HIV-infected patients in south India. World $\mathrm{J}$ Gastroenterol 2007; 13:5015-20

31. Mukhopadhya A. Hepatitis C in India. J Biosci 2008;33:465-73.

32. Devi KH, Brajachand N, Singh HL, Singh YM. Coinfectionby human immune deficiency virus, hepatitis B andhepatitis $\mathrm{C}$ virus in injecting drug users. J Commun Dis 2005;37:73-7.

33. Sahelian R. HIV AIDS supplement vitamin herb information - Natural therapy and treatment. News letter, November 2, 2017. Available from: http://www.raysahelian.com/hiv.html

34. Poordad F, Reddy R, Martin P. Rapid virologic response: A new milestone in the management of chronic hepatitis C. Clin Infect Dis 2008;46:78-84.

35. Sharma R, Duggal N, Malhotra S, Shrivastava D, Hans C. Antifungal susceptibility of Cryptococcus neoformans isolates from fungal meningitis in AIDS patients in India. Int $\mathrm{J}$ Pharm Pharm Sci 2014;6:584-6.

36. Manns MP, Wedemeyer H, Cornberg M. Treating viral hepatitis C: Efficacy, side effects, and complications. Gut 2006;55:1350-9.

37. Carr A, Cooper DA. Adverse effects of antiretroviral therapy. Lancet 2000;356:1423-30

38. Duggan J, Peterson WS, Schutz M, Khuder S, Charkraborty J. Use of complementary and alternative therapies in HIV-infected patients. AIDS Patient Care STDs 2004;15:159-67.

39. Hall CD, Dafni U, Simpson D, Clifford D, Wetherill PE, Cohen B, et al. Failure of cytarabine in progressive multifocal leukoencephalopathy associated with human immunodeficiency virus infection. N Engl J Med 1998:338:1345-51.

40. Manns MP, McHutchison JG, Gordon SC, Rustgi VK, Shiffman M, Reindollar R, et al. Peginterferon alfa- $2 \mathrm{~b}$ plus ribavirin compared with interferon alfa- $2 \mathrm{~b}$ plus ribavirin for initial treatment of chronic hepatitis
C: A randomised trial. Lancet 2001;358:958-65

41. Fried MW, Shiffman MI, Reddy KR, Smith C, Marinos G, Goncales FL, et al. Peginterferon alpha-2a plus ribavirin for chronic hepatitis $\mathrm{C}$ virus infection. N Engl J Med 2002;347:975-82.

42. Soriano V, Nunez M, Miralles C, Berdun MA, Aguirrebengoa K, Ocampo A, et al.The PRESCO trial: Role of Extended Duration of Therapy with Pegylated Interferon Plus Weight Based Ribavirin Doses in 389 HIV-HCV Coinfected Patients. In: International Congress on Drug Therapy in HIV Infection (Glasgow, UK); 2006.

43. Andreoni M, Giacometti A, Maida I, Meraviglia P, Ripamonti D, Sarmati L. HIV-HCV co-infection: Epidemiology, pathogenesis and therapeutic implications. Eur Rev Med Pharmacol Sci 2012;16:1473 83.

44. North CP, Hawkins LK, Rossiter TS, Hawley NM, Bhattacharya R, Landis CS. Sofosbuvir-based regimens for the treatment of chronic hepatitis $\mathrm{C}$ in severe renal dysfunction. Hepatol Commun 2017:1:248 55

45. HCV Guidance: Recommendations for Testing, Managing, Treating Hepatitis C. Infectious Disease Society of America. Initial Treatment of HCV Infection; 2017.Available from: http://www.hcvguidelines.org/ full-report/initial-treatment-hcv-infection.

46. Kumarasamy N, Lai A, Cecelia AJ, Sagayam S, Solomon S, Flanigan TP, et al. Toxicities and Adverse Events Following Generic HAART in South Indian HIV-infected Individuals. $7^{\text {th }}$ International Congress on Drug Therapy and HIV infection, Glasgow, UK, Nov 1418, 2004. Abstract no.P189

47. Mauss S, Valenti W, DePamphilis J, Duff F, Cupelli L, Passe S, et al. Risk factors for hepatic decompensation in patients with $\mathrm{HIV} / \mathrm{HCV}$ coinfection and liver cirrhosis during interferon-based therapy. AIDS 2004;18:F21-5.

48. Lo Re K $3^{\text {rd }}$, Kostman J, Amorosa V. Management complexities HIV/ Hepatitis $C$ virus coinfection in the twenty-first century. Clin Liver Dis 2008;12:587-609.

49. Kumar AP, Parthasarathi G, Sudheer AP, Mothi SN, Swamy VH, Rao S. Incidence and risk factors of renal impairment in hiv-1 infected patients receiving tenofovir based antiretroviral therapy in a south indian hospital. Int J Pharm Pharm Sci 2017;9:152-5.

50. U.S. Department of Health and Human Services. Guidelines for the Use of Antiretroviral Agents in HIV-1-Infected Adults and Adolescents; 2009. Available from: http://www.aidsinfo.nih.gov/guidelines.

51. Lo JC, Mulligan K, Tai VW, Algren H, Schambelan M. "Buffalo hump" in men with HIV-1 infection. Lancet 1998;351:867-70.

52. Cinque P, Koralnik JI, Gerevini S, Miro MJ, Price WR. Progressive multifocal leukoencephalopathy complicating HIV-1 infection. Lancet Infect Dis 2009;9:625-36.

53. Side Effects of HIV and AIDS Drugs.Available from: http://www. webmd.com/hiv-aids/aids-hiv-medication-side-effects.

54. Montessori V, Press N, Harris M, Akagi L, Julio SG. Montaner Adverse effects of antiretroviral therapy for HIV infection. J Appl Math Comput 2004; 170:229-38.

55. Thyagarajan SP, Jayaram S, Gopalakrishnan V, Hari R, Jeyakumar P, Sripathi MS. Herbal medicines for liver diseases in India. J Gastroenterol Hepatol 2002;17:S370-6.

56. Gonçalves D, Lima C, Ferreira P, Costa P, Costa A, Figueiredo W, et al. Orange juice as dietary source of antioxidants for patients with hepatitis C under antiviral therapy. Food Nutr Res 2017;61:1296675.

57. Calland N, Dubuisson J, Rouille Y, Seron K. Hepatitis C virus and natural compounds: A new antiviral approach? Viruses 2012;4:2197-217.

58. Human Metabolome Database (HMDB). Available from: https:// pubchem.ncbi.nlm.nih.gov/source/Human $\% 20$ Metabolome $\% 20$ Database\%20(HMDB).

59. Monforte AD, Lepri AC, Rezza G, Pezzotti P, Antinori A, Phillips AN, et al. Insights into the reasons for discontinuation of the first highly active antiretroviral therapy (HAART) regimen. AIDS 2000;14:499-507. 